\title{
Hospital Nurses' Competencies in Disaster Situations: A Qualitative Study in the South of Brazil
}

\author{
Sandra M. Marin, RN, MN; ${ }^{1}$ Regina R. Witt, RN, $\mathrm{PhD}^{2}$
}

1. Universidade Estadual de Santa Catarina, Chapecó, Santa Catarina, Brazil

2. Universidade Federal do Rio Grande do Sul, Porto Alegre, Rio Grande do Sul, Brazil

\author{
Correspondence: \\ Sandra M. Marin, RN, MN \\ Rua Curitiba 1909 D \\ Bairro Universitário \\ Chapecó, Santa Catarina 89812-185 Brazil \\ E-mail: sandrapeju@hotmail.com
}

Conflicts of interest: none

Keywords: disasters; nursing; professional competencies

Abbreviation:

WHO: World Health Organization

Received: November 3, 2014

Revised: February 25, 2015

Accepted: February 25, 2015

Online publication: October 21, 2015

doi:10.1017/S1049023X1500521X

\begin{abstract}
Introduction: Hospital nurses play a key role in the aftermath of the occurrence of disasters and need specific competencies to work in these situations. From a global perspective, few models exist that focus on disaster nursing.

Problem: This study aimed to identify hospital nurses' competencies in disaster situations. Method: A qualitative, descriptive, exploratory study was developed using focus groups as a method of data collection. Three meetings were held from June through September 2012 with nurses who worked at a hospital used as reference for disaster situations in the South of Brazil. Thematic analysis of collected data generated the competencies. For statement standardization, a format consistent with a verb, a noun, and a complement was adopted. Results: The group validated 17 competencies, which were organized according to the phases of emergency management described by the World Health Organization (WHO) and classified in domain areas of management, health care, communication, and education. Conclusions: The competencies identified in this study can contribute to the education and practice of nurses in the hospital ambience, strengthening its capacity to face disaster situations.
\end{abstract}

Marin SM, Witt RR. Hospital nurses' competencies in disaster situations: a qualitative study in the South of Brazil. Prehosp Disaster Med. 2015;30(6):548-552.

\section{Introduction}

The growth in the number and intensity of disasters has resulted in human, material, and environmental damage with social and economic consequences. In Brazil, this situation has become worrying. The country detects a great amount of road, traffic, and work accidents, and many other disasters such as floods, sliding, fires, gales, hailstorms, epidemics, plagues, and technologic disasters. ${ }^{1}$

This context has demanded actions to mitigate their consequences by measures to preserve the environment and prepare health professional teams. When a disaster occurs, the hospital, within the vast net of emergency services, offers an important entry for casualties. Response depends on a synchronized action taken by a multidisciplinary team, from whom a series of competencies are expected in order to ensure qualified and priority care.

Competence in this context is related to performance when facing situations of unpredictability and complexity and to solving arising problems in a specific cultural context. ${ }^{2}$ Performance of competencies, especially when facing unusual situations with a great number of victims, can guide nurses' practice, along with the multidisciplinary team, in developing assistance needed in an agile and efficient way.

\section{Background}

To assure a global nursing workforce ready to respond in the event of a disaster, competencies are essential. ${ }^{3}$ Documents which describe professional competencies for Public Health Workers' ${ }^{4}$ Mental Health Competencies for Emergency Situations ${ }^{5}$ and Health Worker Competencies for Disaster Education ${ }^{6}$ have been published.

In nursing, research has been developed to identify emergency and preparedness disaster core-competencies for nurses, ${ }^{7}$ and the International Council of Nurses (Geneva, Switzerland) 
established a framework of disaster nursing competencies. ${ }^{3}$ References for nursing education include a set of competencies for the Undergraduate Nursing Curricula developed by the World Health Organization (WHO; Geneva, Switzerland), ${ }^{8}$ Educational Competencies for Registered Nurses developed by the International Nursing Coalition for Mass Casualty Education (American Association of Colleges of Nursing; Washington, DC USA), ${ }^{9}$ and educational strategies for preparing nurses for emergency response. ${ }^{10}$

Although emergency preparedness and response competencies for hospital workers have been defined by the Columbia University Center for Public Health Preparedness (New York, New York USA) in collaboration with the Greater New York Hospital Association (New York, New York USA), ${ }^{11}$ they don't address specifically nurses, and no study or document describes them in Brazil.

Considering the hospital is a major service where victims are taken to, and the complexity and unpredictability of attention in an emergency, hospital nurses' competences in disaster situations are considered an important tool for practice.

Aim

To identify hospital nurses' competencies in disaster situations.

\section{Methods}

Design

A qualitative, descriptive, exploratory study was developed.

\section{Setting}

The setting of the study was a hospital used as reference in disaster situations in the South of Brazil, which serves at least 118 municipalities. Nurses were selected according to the inclusion criteria of more than two years of work experience in the institution, interest in discussing the theme, and availability to attend the meetings. Participants were nominated from a voluntary list resulting in a group of 11 nurses.

\section{Data Collection}

To collect data, focus groups (which is a research technique that uses group sessions as a manner to represent psychological, sociological, and cultural expressions and characteristics) ${ }^{12}$ were used. The meetings were conducted by the researcher, and a nurse, having had experience with research, acted as an observer. Three meetings were developed from June through September 2012.

On the first meeting, the group was informed about the dynamics for the focus groups. General information was offered about the theme of competencies and disasters. The project of investigation was presented and the group setting was established.

On the second meeting, a video about hospital care in emergencies was presented to start reflection about the theme. After that, participants were asked to contribute by presenting three competencies along with the reason why they thought they were important for nurses' practice in disaster situations. A specific formulary was developed for that.

The concept of competence (considered the performance of abilities, aptitudes, skills, along with the underlying knowledge to obtain the professional performance expected) was explained. Explicit orientations about the methodology adopted to develop competencies were offered. Competence statements, in general, should include the following elements: a verb referring to the action; the noun, which is the object of the action; and a complement, which would stipulate how the competence should be performed. ${ }^{13}$ Presentation and discussion of answers followed this phase.

Compiled answers were handed to participants on the third meeting, when the group was divided randomly into three to allow discussion, and asked to consider if each competence should be maintained, modified, or excluded. Each group was then invited to present its conclusions, leading the discussion to the final list of competencies, which were validated.

\section{Data Analysis}

Collected data included transcriptions of meetings, recorded observations, and information provided by participants in the formulary where competencies were indicated. These sources were prepared to allow understanding, interpretation, and inference. Thematic analysis of the collected data was developed by two researchers, independently in its first phases: pre-analysis, material exploration, and treatment of obtained results. After that, interpretation was performed by both researchers in order to set the competencies and proposed classification. ${ }^{14}$

\section{Protection of Human Participants (Ethics)}

Human research ethics approval was obtained from the Institutional Review Board of the Universidade Federal do Rio Grande do Sul (Porto Alegre, Rio Grande do Sul, Brazil). Written informed consent was obtained from all subjects. Each of the respondents fulfilled a separate questionnaire to collect professional and educational data. Colors were used in the questionnaires, as well as by the observer, to assure their anonymity.

\section{Findings}

Nurses' Characteristics

Of the potential participants $(n=48), 11$ practicing nurses were selected. Of them, nine were female, with a mean age of 33 years old $(\mathrm{SD}=6.09$ years $)$, and a mean of eight years $(\mathrm{SD}=3.68$ years $)$ employed in their current position. Their education background included Master's degree $(\mathrm{n}=1)$ and specialization in: Critical Care $(\mathrm{n}=3)$, Occupational Nursing $(\mathrm{n}=2)$, Hospital Management and Infection Control $(n=1)$, and Oncology Nursing $(n=1)$. Their current position in the hospital was in Continuous Education, Security and Occupational Health, Emergency, Supervision, Critical Care, Nursing Management, Maternity, and Infection Control.

\section{Nurses' Competencies}

Of the 29 competencies resulting from the analysis of the material collected on the second meeting, 17 were validated by the focus group. Competencies were not ranked by order of importance but were organized according to the phases and global aspects of the disaster reduction actions of the $\mathrm{WHO}^{15}$ and classified in domain areas. Competencies were classified in the phases of preparedness, with competencies in domain areas of management and education, and the phase of response, with competencies in domain areas of management, health care, and communication. Competencies classified in these domains are presented in Table 1 and Table 2.

\section{Discussion}

Competencies obtained from the study reinforce and give detail to the idea in which, from health professionals, it is expected that they understand the essential elements of effective preparation and response. ${ }^{6}$ 


\begin{tabular}{|c|c|}
\hline Domain & Competence \\
\hline \multirow[t]{3}{*}{ Management } & $\begin{array}{l}\text { Understands how prehospital services are } \\
\text { provided. } \\
\text { Identifies emergency and specialty services in } \\
\text { the region. } \\
\text { Participates in the planning for disaster } \\
\text { situations with other hospitals of the region, to } \\
\text { organize networks of health care. } \\
\text { Participates of the development of a } \\
\text { contingency plan for the hospital. } \\
\text { Develops protocols for health care in a disaster } \\
\text { situation. }\end{array}$ \\
\hline & $\begin{array}{l}\text { Demonstrates knowledge of the institution } \\
\text { structure and capacity to optimize spaces, } \\
\text { distributing patients in the hospital. }\end{array}$ \\
\hline & $\begin{array}{l}\text { Predicts and provides necessary material and } \\
\text { equipment to assist the victims in a disaster } \\
\text { situation. }\end{array}$ \\
\hline \multirow[t]{2}{*}{ Education } & $\begin{array}{l}\text { Maintains technical scientific knowledge in } \\
\text { relevant areas of disaster victims' assistance. }\end{array}$ \\
\hline & $\begin{array}{l}\text { Enablesltrains the nursing team so that } \\
\text { everyone knows their role. } \\
\text { Educates the team about triage and risk } \\
\text { assessment. }\end{array}$ \\
\hline
\end{tabular}

Table 1. Hospital Nurses' Competencies in Disaster Preparedness

\begin{tabular}{|l|l|}
\hline Domain & Competence \\
\hline Management & $\begin{array}{l}\text { Manages and coordinates nursing team in a } \\
\text { disaster situation. }\end{array}$ \\
\cline { 2 - 3 } & $\begin{array}{l}\text { Plans activities, assuring patient and team } \\
\text { safety. } \\
\text { Works collaboratively with the support team to } \\
\text { systematize health care. }\end{array}$ \\
\cline { 2 - 3 } Health Care & $\begin{array}{l}\text { Contributes for the distribution of victims in } \\
\text { hospitals, avoiding services' overload. }\end{array}$ \\
\hline $\begin{array}{l}\text { Demonstrates the knowledge of nursing } \\
\text { actions and directs nursing team during a } \\
\text { disaster situation response. } \\
\text { Develops casualty triage and risk assessment } \\
\text { according to the gravity of each patient. }\end{array}$ \\
\hline Communication & $\begin{array}{l}\text { Receives, organizes, and facilitates } \\
\text { information regarding disaster victims. } \\
\text { Develops a process of communication with all } \\
\text { involved with the victims' assistance. }\end{array}$ \\
\hline
\end{tabular}

Table 2. Hospital Nurses' Competencies in Disaster Response

\section{Hospital Nurses' Competencies in Disaster Preparedness}

Preparedness aims to optimize preventive, response, and reconstruction actions to disasters. It should be based on institutional development of scientific and technological projects regarding: human resources, cultural changes, motivation and enterprise articulation, information and epidemiologic studies on disasters, monitoring, alert and alarm, operational and contingency planning, protection of population at risk, mobilization, rigging, and logistic support. ${ }^{1}$

Management-Management competencies constitute a powerful instrument to transform practice in disaster situations, allowing the evaluation and sizing of problems in a comprehensive way. In this context, nurses must build significant relationships to allow secure practice. ${ }^{6}$

In a disaster situation, emergency departments usually receive patients transported by prehospital services. These services should present the necessary operational and coordination characteristics to answer emergency problems, which include rescue services, medical assistance for the victims at the scene, and transportation, offering an extension of the emergency treatment provided in the hospital.

In Brazil, prehospital services are provided by the Emergency Medical Care Service, responsible for its regulation and assistance with the support of the Fire Department. These services are oriented by protocols, which indicate the procedures to be taken before the patient is delivered to the hospital. ${ }^{16}$

Teamwork requires each member to know what the lines of authority and communication are. Nurses are expected to describe the chain-of-command in emergency response ${ }^{7}$ to demonstrate the ability to seek assistance through the chain-of-command during emergency situations or drills. ${ }^{3}$

In disaster situations, other services are demanded, depending on patients' needs. It's important both to recognize when one is past the limit of one's knowledge, skills, or authority and to know where to direct the request or need so that appropriate answers or services can be provided.

In disaster preparedness, the contribution of the health sector to the inter-sectoral response plan includes the development of contingency plans and coordination mechanisms with the Emergency Medical Services and hospitals (including networks of hospitals, when applicable). ${ }^{3}$ Arranging medical care for disaster situations requires cooperation between different authorities, and considering the importance of complementary care, facilitating the practice of the teams in the hospitals.

Contingency planning is a process leading towards the prior allocation of resources, personnel, equipment, crisis control rooms, tasks, responsibilities, and decision guidance or rules. This is coupled with training, scenario planning, and an array of simulation exercises in a safe environment to ensure that the operational and political-strategic layers within public authorities are best placed to manage any crisis that emerges. ${ }^{17}$

The understanding of the institutional emergency operations plan is considered a competence for health care worker training and education in disaster preparedness and response. ${ }^{6}$ Concerning the nurses, they should be represented on the organization's emergency preparedness committee, and every nurse needs to know where this plan can be found and to be familiar with its contents before an emergency arises. ${ }^{7}$

At the same time, nurse administrators must be sure that the unit, department, or organization they're responsible for has a written emergency preparedness plan. ${ }^{7}$ Nurses should also become familiar with the disaster or emergency plans of their employers, including protocols and contingency plans. Such plans should describe the nurse's role and responsibilities, and the employer's expectations of the nurse, during a disaster or emergency, as well as how these might differ from the usual duties. For example, an 
institutional emergency plan might reassign nurses from non-patient care roles (such as staff educator) to direct patient care roles, as needed. Nurses can seek periodic orientation to the emergency plan, offer suggestions for improvement, and serve on emergency management committees. ${ }^{18}$

In Brazil, the Ministry of Health (Brasília-DF) developed a manual with protocols for 192 diseases and situations that require emergency care. ${ }^{19}$ The establishment of protocols to improve the capacity to respond in emergencies is described for public health professionals. 4

Internally to the hospital, knowledge of the space, activities, and basic equipment of each department/service contributes to agility and quality in health care. ${ }^{19}$ This knowledge brings benefits to the institution with a better use of spaces, with avoiding unnecessary costs and dissemination of contagious diseases, and with improving the healing process of patients.

In Brazil, the nursing team is responsible for dispensing hospital supplies and medications for emergency care to allow stabilization of the clinical condition until the patient can be transferred accordingly to a more complex unit; ${ }^{19}$ this plays an important role in the supply chain logistics. ${ }^{8}$ In Canada, nurses should demonstrate knowledge, skill, and judgment in the management of patients requiring medical devices and specialized equipment. $^{20}$

Education-Health professionals must be trained accordingly to offer the correct answer. ${ }^{21}$ Previous disaster response experience and appropriate disaster education appear to be essential ingredients in providing a prepared and confident workforce. In a community where previous disaster response experience is limited, appropriate disaster education and training for nurses, as well as other health professionals, may increase the level of disaster awareness and may help to make nurses feel less vulnerable when having to face the unexpected. Standardizing disaster education, and making it more available, may create a more cohesive and self-assured workforce. ${ }^{22}$

Participating in continuing education to maintain up-to-date knowledge in relevant areas is a competence expected from nurses, considering that regular continuing education in specific areas can help them keep abreast of the changes on the nature of emergencies, deriving from environmental, political, or societal conditions changes. $^{7^{8}}$

On the framework of Disaster Nursing Competencies developed by the International Council of Nurses, "maintains knowledge in areas relevant to disaster and disaster nursing" and "seeks to acquire new knowledge and maintain expertise in disaster nursing" are competencies classified under the Education and Preparedness area. ${ }^{23}$

Nurses should also seek continuing education from their employers whenever an emergency plan calls for skills they don't already possess. ${ }^{18}$ These competencies are important to qualify health teams about new techniques and forms of organization to address casualties, and are related to the maintenance of life in critical situations, through the incorporation of nurses' abilities, knowledge, and judgment.

Preparedness also intends to make every member of the team understand exactly what their role is during an emergency so that the assistance is executed with no prejudice by gaps or duplications derived from lack of organization and knowledge. In Brazil, the nurse has to apply these principles to the nursing team, because she is responsible for their education and practice.
Specific knowledge and skills required from health care workers responding to a critical event encompass triage, among others, ${ }^{6}$ which consists of a tool that, in addition with organizing the waiting list and proposing another order or service than that of arrival, implies in directing patients for assistance.

According to Brazilian Emergency Policy, the nursing team, physicians, psychologists, social workers, and staff, as the eligible ones to be prepared, should adequate their performance to help nurses develop casualty triage and risk assessment activities. ${ }^{24}$

\section{Hospital Nurses' Competencies in Disaster Response}

The roles most often associated with disaster nursing are visible during the response phase of a disaster when preservation of life and maintenance of health are priorities. ${ }^{3}$ Response includes a group of actions that aim to help the affected population, reduce damage and prejudice, and guarantee essential systems in the community. It involves the application of provision and management principles of care in an emergency situation. ${ }^{8}$

Management-Although health professionals must be prepared to manage human, physical, material, and information resources, management competencies also include activities directed to the patient, its means, resources available for the patient, risk group, and community care. ${ }^{25}$

Management of disaster response depends on the identification of "who needs to know how to do what" 7 in the hospital, where there are many specialties and different teams with distinct abilities and knowledge. Support teams include several services in the hospital, such as the logistics, pharmacy, maintenance, laboratory, nutrition, file, social service, information, admissions, and bed control, that are all enrolled in patient care. This situation is particularly different for nurses in Brazil, because they also are responsible for managing and coordinating the nursing team.

Managing disaster situations also requires awareness of possible contaminants, as well as other risks or imminent threats, and knowledge of appropriate methods of protection. Some emergency response activities require simple universal precautions while others require more sophisticated protections. ${ }^{7}$ Competencies such as "protect self and others from harm," "assess the safety and security issues for self, the response team, and the victims in an emergency situation," and "demonstrate critical event safety principles" have been proposed for health care professionals.

Health care in disaster situations, especially with sudden changes and when it results in an unusual number of casualties, overloads hospitals and health systems, interfering with efficient reaction. Rescue services and support teams work to reestablish essential services, the structure of the affected area, and the moral and well-being of the population, making it possible for them to take their life back in the most adequate possible way. In a situation where available resources are not sufficient to deal with an emergency, there is the necessity of redistributing teams or referring patients to other hospitals. ${ }^{26}$

Health Care-Effective emergency response requires that each team member know what to do and how to do it. This knowledge implies that nurses identify the limits of their own knowledge, skills, and authority, and identify key system resources for referring matters that exceed these limits.

In Brazil, nurses are prepared to perform assessment through history taking, physical assessment, review of records, and 
communication with family and the health care team; ${ }^{20}$ they also apply accepted triage principles when establishing care based on available resources and facilitate a more professional approach for the implementation of nursing care for individuals and families. ${ }^{8}$

Communication-One of the major challenges in the first hours after the occurrence of a disaster is to ensure that clear information is disseminated reflecting the prior necessities of the affected populations. This information is something everyone seeks and needs to make decisions, and overall, to offer timely, agile, and adequate response to those affected by a disaster. ${ }^{27}$

Coping strategies for disasters require mass-communication tools such as community, electronic media, radio, and television. In this context of the health professionals, it is expected to relate with the press by means of a partnership with the Operation Command System of the Civil Defense.

Nurses should be prepared to apply principles of communication and interpersonal relationships in an emergency situation. ${ }^{8}$ They usually are required to collaborate in this process because of the continuum of care, synthesizing and integrating information from Emergency Department Systems with knowledge relevant to

\section{References}

1. Brasil Ministério da Integração Nacional. Secretaria Nacional de Defesa Civil. Política Nacional de Defesa Civil. Brasília, DF, Brasil: Ministério da Integração Nacional; 2007.

2. Almeida MA. Concepções de discentes e docentes sobre competências na enfermagem. Rev Gaúcha Enfem. 2004;25(2):184-193.

3. International Council of Nurses. ICN framework of disaster nursing competencies. ICN Web site. http://myweb.polyu.edu.hk/ hswhocc/resource/D/2009DisasterNursing Competencies.pdf. Published 2009. Accessed May 13, 2014.

4. Gebbie K, Merrill J. Public health worker competencies for emergency response. J Public Health Manag Pract. 2002;8(3):73-81.

5. Iowa Department of Public Health Mental Health Competencies Task Force. Mental health competencies for health care providers for terrorism and emergency preparedness and response. http://www.idph.state.ia.us/adper/common/pdf/mh brochure.pdf. Published 2006. Accessed May 13, 2014.

6. Hsu EB, Thomas TL, Bass EB, Whyne D, Kelen GD, Green GB. Health care worker competencies for disaster training. BMC Med Educ. 2006;6:19.

7. Gebbie K, Qureshi K. Emergency and disaster preparedness: core competencies for nurses. Am J Nurs. 2002;102(1):46-51.

8. World Health Organization. Integrating Emergency Preparedness and Response into Undergraduate Nursing Curricula. Geneva, Switzerland: World Health Organization; 2008.

9. International Nursing Coalition for Mass Casualty Education. Educational competencies for Registered Nurses responding to mass-casualty incidents. http://www.aacn.nche.edu/ education/pdf/INCMEcompetencies.pdf. Published 2003. Accessed August 12, 2014.

10. Weiner E. Preparing nurses internationally for emergency planning and response. Online J Issues Nurs. 2006;11(3):4.

11. Center of Public Health Preparedness, Columbia University Mailman School of Public Health; Columbia University School of Nursing; the Greater New York Hospital Association. Emergency preparedness response competencies for hospital workers. http://www.ncdp.mailman.columbia.edu/files/hospcomps.pdf. Published 2003. Accessed June 10, 2014.

12. Gaskell G. "Entrevistas individuais e grupais." In: Bauer MW, Gaskell G. Pesquisa Qualitativa com Texto, Imagem e Som: Um Manual Prático, 4th edition. Petrópolis, RJ, Brasil: Vozes; 2005: 72-88. emergency care. Communication with families and health teams is also considered important for the evaluation of casualties. ${ }^{9,20}$

Appropriate communication between professions during an emergency response is an indispensable component to developing solid interactions within the management team, which promotes a professional relationship that facilitates the work of all.

\section{Study Limitations}

This study was limited to a hospital in the South of Brazil and reflects nurses' experiences while working there. Although this experience fulfills Delphi Technique Criteria for selection of experts, no input other than the researchers' was obtained. At the same time, competencies derived are proposed but not yet validated by actual testing or research in disaster events.

\section{Conclusion}

The study resulted in 17 competencies validated by a focus group, organized according to the phases and global aspects of the disaster reduction actions of the $\mathrm{WHO}$, and classified in the phases of preparedness and response and domain areas of management, education, health attention, and communication.

13. Ramos MN. A Pedagogia das Competências: Autonomia ou Adaptação? São Paulo, SP, Brasil: Cortez; 2001

14. Minayo MCS. O Desafio do Conhecimento: Pesquisa Qualitativa em Saúde, 12th edition. São Paulo, SP, Brasil: Hucitec; 2010.

15. Organización Panamericana de la Salud. Índice de Seguridad Hospitalaria: Guía del Evaluador de Hospitales Seguros. Washington, DC USA: OPAS; 2008.

16. Brasil Ministério da Saúde. Protocolos da Unidade de Emergência, 10th edition. Brasília, DF, Brasil: Ministério da Saúde; 2002.

17. Mabaso E, Manyena SB. Contingency planning in Southern Africa: events rather than processes? Jàmbá: Journal of Disaster Risk Studies. 2013;5(1):1.

18. Martin DS, Brown LM, Reid WM. Predictors of nurses' intentions to work during the 2009 Influenza A (H1N1) pandemic. Am J Nurs. 2013;113(12):24-31.

19. Brasil Ministério da Saúde. Política Nacional de Atenção às Urgências, 3rd edition. Brasília, DF, Brasil: Ministério da Saúde; 2006.

20. Harper S, Hartwick E. Nursing Competency-based Orientation Program. Peterborough, Ontario, Canada: Regional Health Centre; 2006.

21. Lee D. Disaster planning. Br Jour Perioper Nurs. 2003;13(11):454-454.

22. Duong K. Disaster education and training of emergency nurses in South Australia. Australas Emerg Nurs J. 2009;12(3):86-92.

23. International Council of Nurses. Nurses and Disaster Preparedness. Geneva, Switzerland: ICN; 2003.

24. Brasil Ministério da Saúde. Portaria $n^{\circ} 1600$, de 7 de Julho de 2011: Reformula a Politica Nacional de Atenção às Urgências e Institui a Rede de Atenção as Urgências no Sistema Único de Saúde (SUS). Brasília, DF, Brasil: Ministério da Saúde; 2011.

25. Witt RR, Almeida MCP. Identification of nurses' competencies in primary health care through a Delphi study in Southern Brazil. Public Health Nursing. 2008;25(4):336-338.

26. Brasil Ministério da Integração Nacional. Política Nacional de Defesa Civil, Planejamento Nacional para Gestão de Risco. Brasília, DF, Brasil: Ministério da Integração Nacional; 2007.

27. Universidade Federal de Santa Catarina. Centro Universitário de Estudos e Pesquisas Sobre Desastres. Comunicação de Riscos e de Desastres [Curso a Distancia]. Florianópolis, SC, Brasil: CEPED; 2010. 